\title{
Biogenous ethers: production and operation in a diesel engine
}

\author{
Aleksandar Damyanov ${ }^{1}$ (D) Peter Hofmann ${ }^{1} \cdot$ Bernhard Geringer $^{1} \cdot$ Nikolaus Schwaiger $^{2} \cdot$ Thomas Pichler $^{2}$. \\ Matthäus Siebenhofer ${ }^{2}$
}

Received: 15 January 2018 / Accepted: 19 April 2018 / Published online: 26 April 2018

(c) The Author(s) 2018

\begin{abstract}
Fuels from lignocellulosic biomass have the potential to contribute to sustainable future mobility targets by reducing the fossil $\mathrm{CO}_{2}$ emissions of the transport sector. Of special interest for the diesel engine are oxygenated fuels, since they can help to solve traditional conflicts of objectives like the soot-NO $x$ trade-off or the efficiency-NO $x$ compromise. Dibutyl ether (DBE) and oxymethylene ethers (OME) are among the most promising fuel candidates. The suitability of these compounds for diesel engines is investigated in this study. The fuels are injected in pure form as well as a diesel-biofuel blend with $20 \%$ volumetric biogenic share. During the course of these investigations special attention is given to soot and particle emissions, and also to measured engine efficiency. The combustion tests are combined with an analysis of suitable production paths of the evaluated bio-ethers as second generation biofuels. Production simulation shows high greenhouse gas savings potential, but also high investment costs.
\end{abstract}

Keywords Diesel engine · Dibutyl ether · Biofuel · Polyoxymethylene dimethyl ether · OME · POMDME · Biomass pulping

\begin{tabular}{ll}
\multicolumn{2}{l}{ Abbreviations } \\
DBE & Dibutyl ether \\
OME & Oxymethylene ether \\
POMDME & Polyoxymethylene dimethyl ether \\
CEC & Certified test diesel fuel \\
MTHF & Methyltetrahydrofuran \\
HFRR & High-frequency reciprocating rig \\
FAME & Fatty acid methyl ester \\
PTFE & Polytetrafluoroethylene
\end{tabular}

Aleksandar Damyanov

aleksandar.damyanov@ifa.tuwien.ac.at

Peter Hofmann

peter.hofmann@ifa.tuwien.ac.at

Bernhard Geringer

bernhard.geringer@ifa.tuwien.ac.at

Nikolaus Schwaiger

nikolaus.schwaiger@tugraz.at

Thomas Pichler

thomas.pichler@tugraz.at

Matthäus Siebenhofer

m.siebenhofer@tugraz.at

1 Institute for Powertrains and Automotive Technology, Vienna University of Technology, Vienna, Austria

2 Institute of Chemical Engineering and Environmental Technology, Graz University of Technology, Graz, Austria

$\begin{array}{ll}\text { MFB } & \text { Mass fraction burned } \\ \text { EGR } & \text { Exhaust gas recirculation } \\ \text { CAaTDC } & \text { Crank angle after top dead center } \\ \text { EOI } & \text { End of injection } \\ \text { SOI } & \text { Start of injection } \\ \text { PM } & \text { Particle matter (mass) } \\ \text { PM\# } & \text { Particle number }\end{array}$

\section{Introduction}

Climate change concerns and legislative regulations require adequate measures to reduce the human impact on global warming. Increasing production and usage of renewable energy are seemingly the key to a biocarbon-based future and an economic as well as energetic independence from fossil fuels on a global scale. The transport sector contributes to about $23 \%$ [1] of the total greenhouse gas emissions in the European Union. Therefore, reducing $\mathrm{CO}_{2}$ from traffic is crucial to achieve the desired climate-stabilizing objectives. Along with improvements in the efficiency of the internal combustion engines, the focus should be extended to defossilization of the fuels used.

Diesel engines with their high efficiency are of great importance for the transport of passengers and goods. However, the typical exhaust gas emissions from the combustion 
of conventional diesel fuel make further development inevitable, if future air quality regulations are to be met. Second generation biofuels have the potential to reduce the $\mathrm{CO}_{2}$ emissions of the transport sector, while simultaneously mitigating ethical questions surrounding the issue of food production. Furthermore, oxygenated fuels provide beneficial combustion properties and can help to solve traditional conflicts of objectives like the soot-NO $x$ trade-off or the efficiency-NO $x$ compromise. Among many candidates dibutyl ether (DBE) and oxymethylene ethers (OME) are discussed to be promising alternatives to fossil fuels for future diesel engine powering. They can completely substitute diesel or may be mixed with it. Polyoxymethylene dimethyl ethers (POMDME, also called oxymethylene ethers or OME), are known to provide almost soot-free combustion and their usage might wipe out major constraints of diesel engines by reducing emissions and improving efficiency. Dibutyl ether on the other hand, possesses very high ignitability and advantageous molecule structure.

Lignocellulosic biomass is a sustainable, renewable energy source and serves as a feed material for the production of the bio-ethers discussed in this study. Dibutyl ether may be produced through biomass pulping, whereas oxymethylene ethers are obtained through biomass gasification [2].

Dibutyl ether is a volatile, colourless liquid with a fruity smell. Due to its high reactivity DBE shows a very short ignition delay [3] and some researchers use it as an ignition booster in blended fuels [4-7]. Tests with neat DBE in [3, 6] indicate that $\mathrm{HC}, \mathrm{CO}$ and noise emissions are significantly reduced compared to diesel in most of the investigated operating points. DBE usage results in almost soot-free combustion according to $[3,6]$. The authors give an approximate cetane number of 115 for DBE and explain that DBE and diesel combustion occur in a similar way and produce many soot precursors, as a result of which high soot emissions are expected. However, the oxygen content in the molecule and a different soot-oxidizing mechanism overcome the negative influence of the high ignitability and minimize the particulate matter emissions [8] examines the soot-oxidizing mechanism in the process of DBE combustion and reports missing soot luminescence in the post-oxidation combustion phase, probably resulting from a mechanism unusual for pure hydrocarbons and different particle composition. Additionally, [9] points out the very good mixture formation properties of DBE, which are a consequence of low viscosity (dynamic viscosity $0.64 \mathrm{mPa} . \mathrm{s}$ at $25{ }^{\circ} \mathrm{C}$ [3]), low boiling temperature and low heat of vaporization. These aspects result in high Reynolds numbers and a proper spray break-up $[9,10]$. As stated in [11], the spray structure of neat DBE and its blends with diesel fuel show a larger spray angle and shorter liquid penetration length than pure diesel, providing improvements to atomization behaviour.
The properties of oxymethylene ethers depend on the molecule size and therefore on the number of oxymethylene units $\left(-\mathrm{CH}_{2} \mathrm{O}-\right)$. The resulting formula is $\mathrm{H}_{3} \mathrm{C}-\mathrm{O}\left(-\mathrm{CH}_{2} \mathrm{O}-\right)_{n}-\mathrm{CH}_{3}$, with $n=0$ for DME (the simplest ether) and $n=1$ for dimethoxymethane (OME1, the simplest oxymethylene ether and the full acetal of formaldehyde and methanol). Molecule size with $n \leq 6$ offers combustion properties for alternative fuels. Oxymethylene ethers may be simply specified as $\mathrm{OME}_{n}$. They are colourless liquids, their specific mass, cetane number and kinematic viscosity rise with molecule length. The main factors, which are responsible for nearly sootless combustion, are the high oxygen content of over $45 \mathrm{wt} \%$ and the absence of $\mathrm{C}-\mathrm{C}$ bonds (C1 oxygenates). The significantly lower calorific value of OMEs can be considered as a disadvantage compared to conventional diesel. Generally, OME3-6 are found to have the best suitability for diesel engine applications, since their properties (boiling point, lubricity, viscosity) are closest to diesel [12-15].

Most of the OME combustion investigations found in literature discuss OME1 or mixtures of diesel and OME1. Until now, higher grade OMEs have been extremely difficult to synthesize. Exhaust soot emissions are reduced by OME1 add-on to diesel [16], the real advantage of OME, however, is demonstrated by using it as a pure substance $[14,17,18]$. In this case, the soot-NO $x$ trade-off is avoided. It is proven that higher methane emissions are produced, when the engine is operated with OME1 or OME2 at nearstoichiometric conditions. Soot and particle emission characteristics of both fuels are very similar [13]. The tests with a mixture of the higher OME3-6 and the comparison of combustion results with OME1 and paraffinic diesel fuel in [12, $19,20]$ confirm the previous findings of extremely low soot and particle emissions from OME combustion.

\section{Tested fuels}

In this study, a certified diesel fuel is used as reference for comparison and is briefly referred to as CEC. Dibutyl ether (DBE) is the first representative of the investigated oxygenated fuels. It is characterized by a low ignition temperature and therefore a very high cetane number of approx. 100 [6]. $1000 \mathrm{ppm}$ of monocarboxylic acid is added to DBE to ensure sufficient lubricity. The gravimetric oxygen share of $13.1 \%$ in the DBE molecule is relatively low compared to the $40.3 \%$ in the second investigated fuel OMEmix. OMEmix stands for a mixture of the higher OMEs $n=2-6$. Its main components are OME3 (78.7\%) and OME4 (19.8\%) (area percent gained in the gas chromatographic analysis, in this case approx. weight \%). Figure 1 displays the structural formula of the ethers used. 


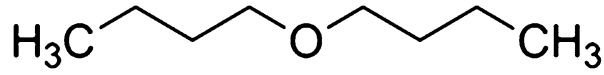 Dibutylether}

\section{Oxymethylenether $\mathrm{H}_{3} \mathrm{C}$ ○「的 $\mathrm{CH}_{3}$}

Fig. 1 Structural formula of the investigated fuels

The investigated compounds are injected into the combustion chamber both as a neat fuel and as a diesel-biofuel blend. The Renewable Energy Directive 2009/28/EC suggests a $10 \%$ renewable content in the fuel used for transport applications [21]. Most of it is assumed to be achieved by fuel blends with biogenous share. This value, however, is only applicable in regard to the mean value of the biocontent in transportation fuels. In order to further explore the potential of oxygenated biofuel add-on, the substitution rate for the engine tests in this study accounts for 20 vol\%. The biogenic share of energy in the OMEmix/diesel blend is $12.6 \%$, the corresponding biogenic energy share in the DBE/diesel blend is $16.8 \%$. All fuels were analysed and the most important results are summarized in Table 1. The heat of vaporization of DBE is quoted in [3] and the viscosity of the OME blends in [22].

\subsection{Production pathways of biogenous fuels}

For DBE production, the pulping process of an ethanol organosolv process is simulated. The main components of lignocellulose (cellulose, hemicellulose and lignin) are separated. Afterwards, hemicellulose and cellulose are converted into fuels by fermentation and/or reactive processes and synthesis routes. Non-converted biomass fractions, such as lignin or hemicellulose may be combusted. A concept scheme of the biomass conversion is shown in Fig. 2 [23]. In this study, two different cases of side stream treatments are compared.

The first case (case 1) is an integrated conversion of the hemicellulose fraction into 2-methyltetrahydrofuran (2-MTHF) and the second case (case 2) is the thermal conversion of hemicellulose for steam and power generation.

Plant size is set on an industrial scale with a biomass consumption of $101 \mathrm{t} / \mathrm{h}$. This is the same order of magnitude as proposed in literature [24]. Biomass source is the energy plant Miscanthus sinensis and process operation is based on the work of Alriols [25]. To increase production rates, initial production route is improved. The ethanol organosolv process is auto-catalysed by acetic acid, which is formed during the pulping process.

During ethanol organosolv pulping $40.7 \mathrm{t} / \mathrm{h}$ cellulose is gained. Cellulose is converted into glucose by enzymatic hydrolysation. Subsequent fermentation of glucose yields in acetone, butanol and ethanol. Product separation is performed by distillation. Product separation has to overcome one azeotrope of water and ethanol and additional one azeotrope of water and butanol. With this simulated process route $9.3 \mathrm{t} / \mathrm{h}$ butanol is produced and additional $2.9 \mathrm{t} / \mathrm{h}$ of acetone is gained. The ethanol formed is used for the pulping process to compensate ethanol losses. Additional need of energy is
Table 1 Properties of the tested fuels

\begin{tabular}{llllll}
\hline & CEC diesel & DBE & $20 \%$ DBE & OMEmix & 20\% OMEmix \\
\hline Structural formula & $\mathrm{C}_{12} \mathrm{H}_{23}{ }^{\mathrm{a}}$ & $\mathrm{C}_{8} \mathrm{H}_{18} \mathrm{O}$ & $\mathrm{C}_{11} \mathrm{H}_{22} \mathrm{O}_{0.2}{ }^{\mathrm{a}}$ & $\mathrm{C}_{5.2} \mathrm{H}_{12.4} \mathrm{O}_{4.2}{ }^{\mathrm{a}}$ & $\mathrm{C}_{10} \mathrm{H}_{20} \mathrm{O}^{\mathrm{a}}$ \\
Cetane number $(-)$ & 54.5 & $\sim 100$ & 63.2 & 52.8 & 52.1 \\
Density $\left(15^{\circ} \mathrm{C}\right)\left(\mathrm{kg} / \mathrm{m}^{3}\right)$ & 833.5 & 773 & 820 & 1046 & 876 \\
Lower calorific value $(\mathrm{MJ} / \mathrm{kg})$ & 42.68 & 37.42 & 41.57 & 19.4 & 37.36 \\
HFRR $(\mu \mathrm{m})$ & 413 & & & 409 & \\
$\mathrm{C}$-fraction $(\mathrm{wt} \%)$ & 85.4 & 72.2 & 83 & 43.3 & 74.8 \\
$\mathrm{H}$-fraction $(\mathrm{wt} \%)$ & 14.2 & 13,8 & 13.8 & 8.7 & 12.5 \\
O-fraction $(\mathrm{wt} \%)$ & - & 13.1 & 2.4 & 47.9 & 11.8 \\
$\mathrm{H} / \mathrm{C}-$ ratio $($ atomic) & 1.92 & 2.25 & 1.97 & 2.416 & 1.98 \\
Boiling point $\left({ }^{\circ} \mathrm{C}\right)$ & $173-363$ & 141 & $141-363$ & $105-197$ & \\
Stoichiometric ratio $(\mathrm{kg} / \mathrm{kg})$ & 14.5 & 12.8 & 14.2 & 5.9 & 12.44 \\
Air demand for stoichiometric & 0.340 & 0.342 & 0.341 & 0.304 & 0.333 \\
$\quad$ combustion $(\mathrm{kg} / \mathrm{MJ})$ & & & & & \\
Heat of vaporization $(\mathrm{kJ} / \mathrm{kg})$ & 358 & 286.8 & & & $\sim 2$ \\
Kin. viscosity $\left(40{ }^{\circ} \mathrm{C}\right)\left(\mathrm{mm}{ }^{2} / \mathrm{s}\right)$ & 2.4 & & & 0.96 & \\
\hline
\end{tabular}

${ }^{a}$ Approximative assumption for calculation purposes 
Fig. 2 Concept scheme for biomass conversion into fuels using organosolv pulping [23]

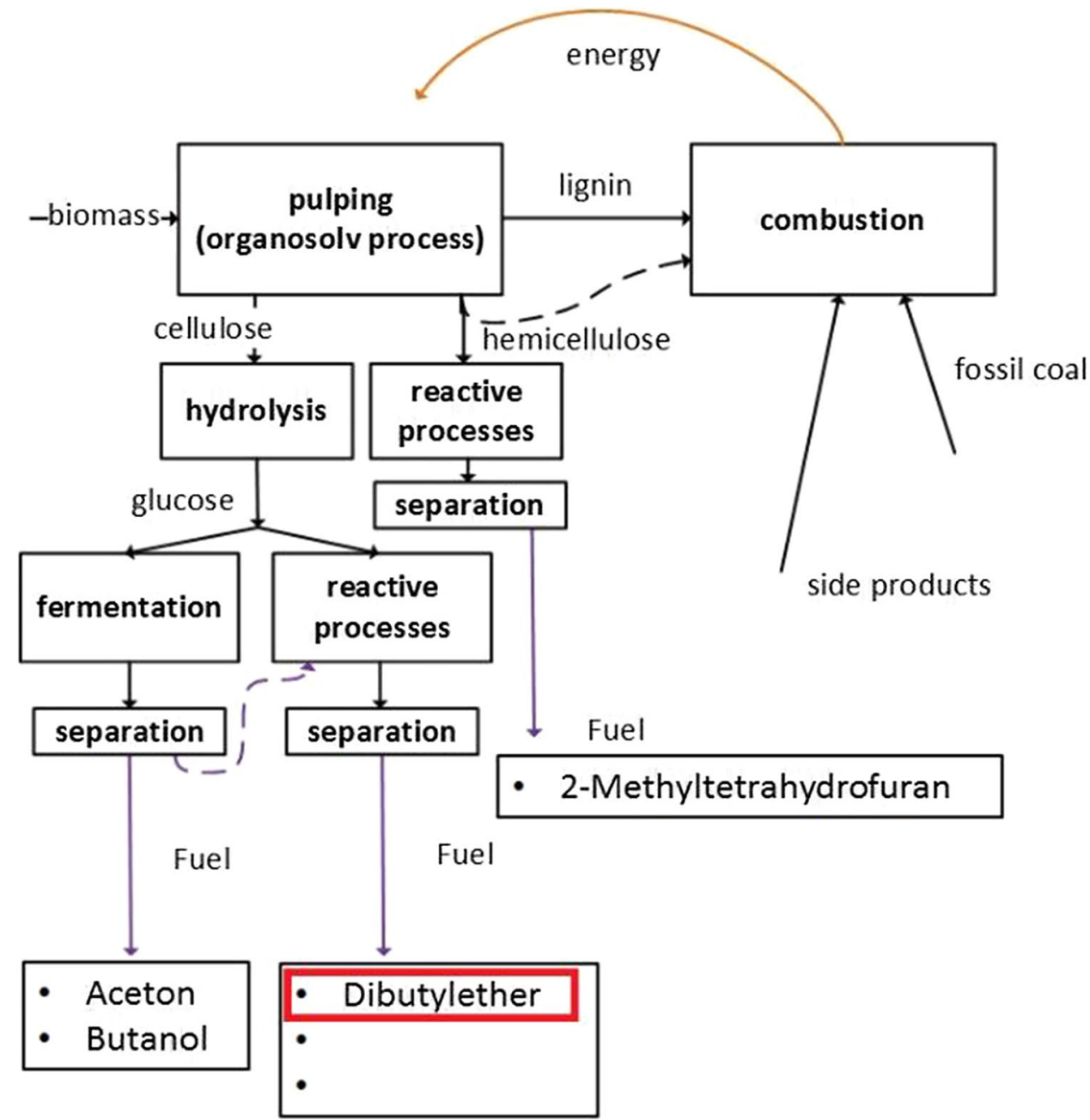

provided by coal combustion with a calculated $\mathrm{CO}_{2}$ output of $111.3 \mathrm{~g}_{\mathrm{CO} 2} / \mathrm{MJ}$ [26].

DBE can be produced by dehydration of butanol. The reaction may be carried out with different catalysts. Butene and water are the main byproducts; see Eqs. 1 and 2:

DBE formation: $2 \mathrm{C}_{4} \mathrm{H}_{10} \mathrm{O} \rightarrow \mathrm{C}_{8} \mathrm{H}_{18} \mathrm{O}+\mathrm{H}_{2} \mathrm{O}$,

Butene formation: $\mathrm{C}_{4} \mathrm{H}_{10} \mathrm{O} \rightarrow \mathrm{C}_{4} \mathrm{H}_{8}+\mathrm{H}_{2} \mathrm{O}$.

The selectivity of the reaction products is strongly dependent on the reaction conversion. For the DBE production a conversion of $50 \%$ is assumed, whereas reaction temperature is $237^{\circ} \mathrm{C}$ [27]. In this case a particularly high selectivity for DBE is evident when using an $\mathrm{Al}_{2} \mathrm{O}_{3} / \mathrm{SO}_{4}$ catalyst. Thus, $71.1 \mathrm{~mol} \%$ of the butanol is converted to DBE and $27.9 \mathrm{~mol} \%$ to butene [28]. Not converted butanol is recirculated and butene is used for energy generation. Eventually DBE is being purified through methods of extraction and distillation [27].

The production technology is an essential aspect also in the OME discussion. Based on preliminary OME production path analysis [29-34], [35] continues the investigations and makes an assessment of OME production costs and concludes that the production is competitive to conventional diesel fuel production. The feed stock for OME production in the cited study is, however, market available methanol and it has to be assumed that it is of fossil origin. OME production routes are also discussed in [36, 37], but an economic review is not made in these studies.

In the present study, bio-OME production from lignocellulose is assessed and evaluated in a shortcut simulation. Basis is the production of 250.000 t/a of an OMEmix. Biomass gasification and subsequent methanol synthesis is determined as reaction pathway. Figure 3 shows a schematic overview of OMEmix production from lignocellulosic feed.

Feed material in the calculations is spruce wood. Theoretical plant operating hours are $8000 \mathrm{~h} / \mathrm{a}$. It is assumed that the whole biomass pre-treatment is part of the fuel production at a single biorefinery site. Biomass feed is $95 \mathrm{t} / \mathrm{h}$ spruce wood. After chipping with a drum chipper, this biomass amount corresponds to $368 \mathrm{~m}^{3}$ of wood with a moisture content of $15 \%$ [38]. Selected gasification 
Fig. 3 OMEmix production based on lignocellulosic feed [20]

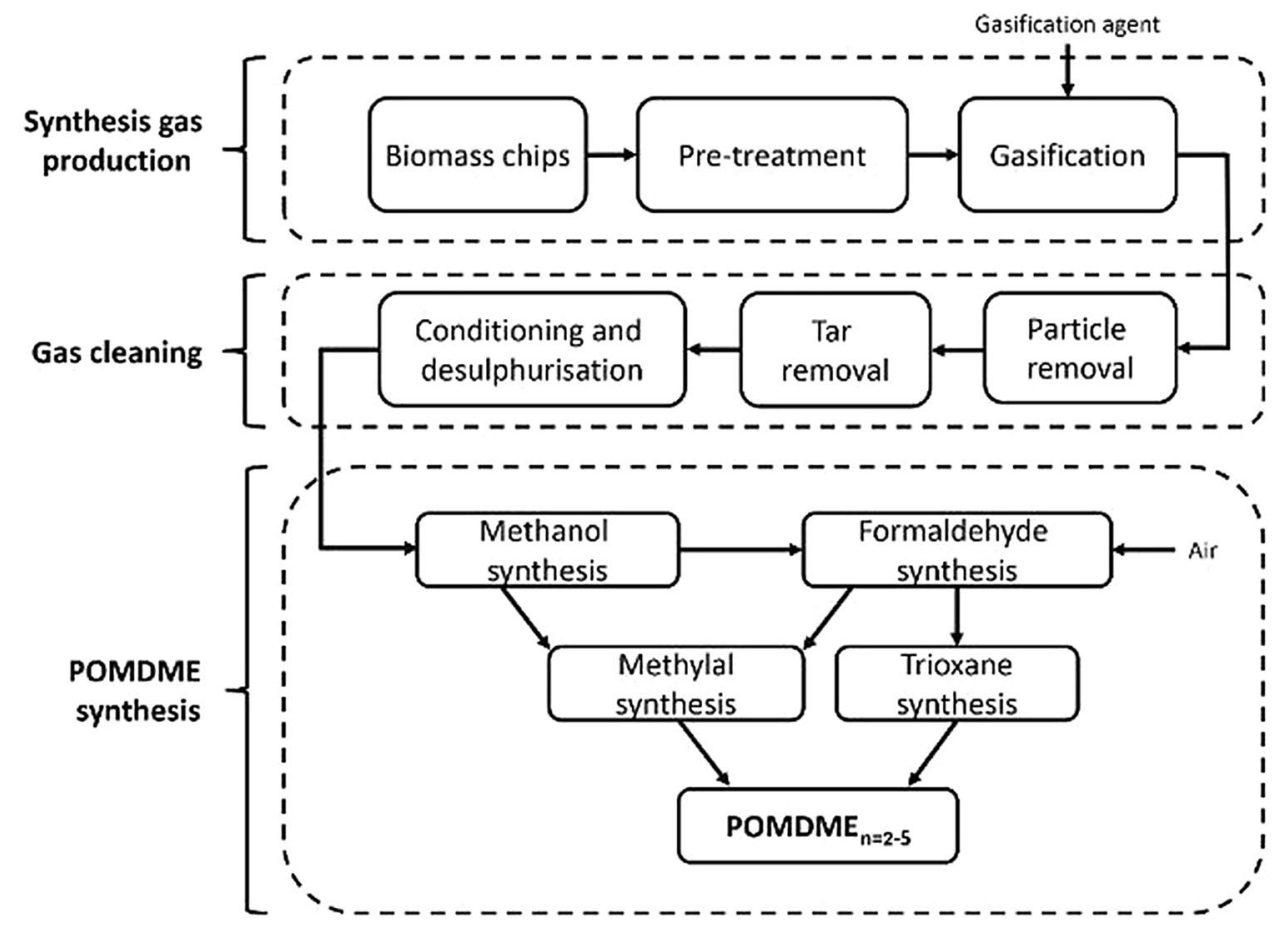

process is the Carbo-V process, operated by Linde [39]. The Carbo-V process is a stepwise biomass gasification process. First step is a $450{ }^{\circ} \mathrm{C}$ flash-type pyrolysis, followed by an entrained flow gasifier for gaseous products and finally a fluidized bed gasifier for biochar gasification [40]. The Carbo-V process is limited to a scale of $160 \mathrm{MWth}$ fuel capacity, this corresponds to $720 \mathrm{t} / \mathrm{day}$ of bone dry biomass. Due to this fact a design of three parallel gasification units is performed. Gas cleaning is modelled with a Selexol process [41]. To reach final sulphur concentration of less than $0.1 \mathrm{ppm}$ in the feed gas, a metal absorber is applied. Methanol synthesis is simulated based on a slurry reactor of Air Products Liquid Phase Conversion Company in an LPMeOH (low-pressure methanol synthesis) process [42]. According to Fig. 3, the next building block in the OME process chain is formaldehyde. Formaldehyde production is simulated with the BASF process [43] to provide $22.000 \mathrm{~kg} / \mathrm{h}$ formaldehyde for methylal and trioxane formation. Trioxane production is modelled based on the method of Grützner [44] and formaldehyde conversion is estimated with $100 \%$, due to the application of a recycle stream. Additionally to trioxane, methylal is the second building block for OME production. A reactive distillation, with water as entrainer, according to Liu [45] is simulated and product purity of $98.7 \%$ is reached. Finally, the production of OME mixture was calculated following the design of Burger et al. [34, 46]. This design is based on a packed bed reactor with the acidic Amberlyst 46 catalyst, with three subsequent distillation columns for product separation. Based on this model OME production is evaluated.

\subsection{Production evaluation}

Biofuel production is evaluated based on its industrial production needs and setup. Evaluation criteria are as follows:

- Energetic fuel efficiency Evaluation of the transfer rate of the chemical bound energy into the fuel fraction $\left(\mathrm{MJ}_{\text {Biomass }} / \mathrm{MJ}_{\text {Fuel }}\right)$.

- Process effort Estimation of production costs of fuel production ( $€ / \mathrm{MJ}_{\text {Fuel }}$ ) (includes biomass price, transport costs, production auxiliaries, energy costs as far as achievable).

- Greenhouse gas reduction Calculations of greenhouse gas emissions of biofuels based on EU-Directive 2009/28/EG including cultivation and harvest, transport and production processes [21] and a comparison with standard diesel $\left(\% \mathrm{CO}_{2}\right)$.

- Investment costs Based on cost estimations and correlations of existing plants $\left(€ / \mathrm{L}_{\text {Fuel }}\right)$.

Table 2 shows the results of the simulation. Based on these calculations the production of the investigated bioethers is possible and feasible. To show a comparison with a first generation biofuel, a sodium methanol-based biodiesel plant for rape seed oil conversion into biodiesel is simulated. 
Table 2 Results of biofuel production simulation $[20,27$, 47]

\begin{tabular}{lllll}
\hline Fuel & $\begin{array}{l}\text { Energetic fuel efficiency } \\
\left(\mathrm{MJ}_{\text {biomass }}\left(\mathrm{MJ}_{\text {Fuel }}\right)\right.\end{array}$ & $\begin{array}{l}\text { Greenhouse gas } \\
\text { reduction }\left(\% \mathrm{CO}_{2}\right)\end{array}$ & Process effort $\left(€ / \mathrm{MJ}_{\text {Fuel }}\right)$ & $\begin{array}{l}\text { Invest } \\
\text { costs }(€ / \\
\left.\mathrm{L}_{\text {Fuel }}\right)\end{array}$ \\
\hline FAME & 1.01 & 38 & 0.026 & 0.006 \\
DBE (case 1) & 3.5 & -57.5 & $0.023-0.035$ & 0.390 \\
DBE (case 2) & 5.5 & 67.1 & $0.017-0.039$ & 0.627 \\
POMDME & 2.77 & 70.9 & 0.025 & 0.224 \\
\hline
\end{tabular}

Process effort: without taxes, biomass price $34.2 € / \mathrm{m}^{3}$ without bark and at forest site (for POMDME) and 8-80 €/t (for miscanthus), personnel costs: 2 persons per unit operation in 5 shift operation according to Austrian wage agreement chemical industry, excluding catalyst costs for DBE production and CO-Shift, formaldehyde synthesis, methylal synthesis, trioxane synthesis; maintenance costs: $2.5 \%$ of investment costs; transport of biomass and products of max. $200 \mathrm{~km}$ (average $93.7 \mathrm{~km}$ ), $25 \%$ train and $75 \%$ truck transport; investment costs: based on correlations [48] and chemical engineering plant cost index for 2014 with 579.8

Based on the process simulation, mass and energy balances of the two cases for DBE production are compared. Organosolv process fuels result from complex interconnections in a biorefinery with a production of several fuels at the same time. In many cases total processes based on the ethanol-organosolv-pulping with separate conversion of cellulose and hemicellulose have no positive $\mathrm{CO}_{2}$ savings. If the fraction of hemicellulose is thermally utilized, positive $\mathrm{CO}_{2}$ savings are achieved. As can be seen in Table 2 only the second case for DBE production, where hemicellulose is used to cover energy needs, results in a greenhouse gas reduction.

It turns out that the plant costs of the established production of biodiesel are much lower than the investment costs needed for innovative manufacturing processes. At the same time FAME shows a significantly better energetic fuel efficiency, since the production of DBE or OMEmix with the same energy content requires much more biomass feed. However, the process effort for the manufacturing of the bio-ethers is comparable to biodiesel, and is caused by the high rape seed oil price. The great advantage of these innovative fuels lies in their very high potential for $\mathrm{CO}_{2}$ reduction of $67 \%$ (DBE) and 71\% (OMEmix) towards fossil diesel, whereas biodiesel achieves only about $38 \%$ in this aspect. Furthermore, rape seed does not belong to the second generation biofuels and its availability is limited, whereas feed stock for DBE and OMEmix is highly available.

\section{Test engine and test methodology}

A modern in-line four-cylinder diesel engine is used as a test engine. The low availability and the high purchase costs of the fuels make single cylinder operation reasonable. Only the first cylinder is fired, the other three are deactivated and their gas exchange is separated from the gas exchange of the fired cylinder. The cylinder has a displacement of $537 \mathrm{~cm}^{3}$ and a compression ratio of 17.5. Bore and stroke are 88 and $88.34 \mathrm{~mm}$, respectively. The original high-pressure common rail injection system is equipped with seven-holes nozzles solenoid injectors. Charging is performed with an external electrically driven supercharger. An electrically adjustable flap valve is used to adjust the necessary exhaust gas back pressure. Cooled high-pressure exhaust gas recirculation is applied. The standard exhaust gas aftertreatment system has been removed. Emissions sampling takes place in the raw exhaust gas. The temperatures of the charge air and the fuel are conditioned. The standard sealing materials in the fuel system are inappropriate for the tested fuels and are replaced with PTFE seals. Figure 4 shows a schematic overview of the test bench.

The test engine is equipped with high- and low-pressure indication and standard exhaust gas measurement, as well as AVL Micro Soot Sensor 483 and AVL Particle Counter 489. Additionally an AVL Smoke Meter 415S is used.

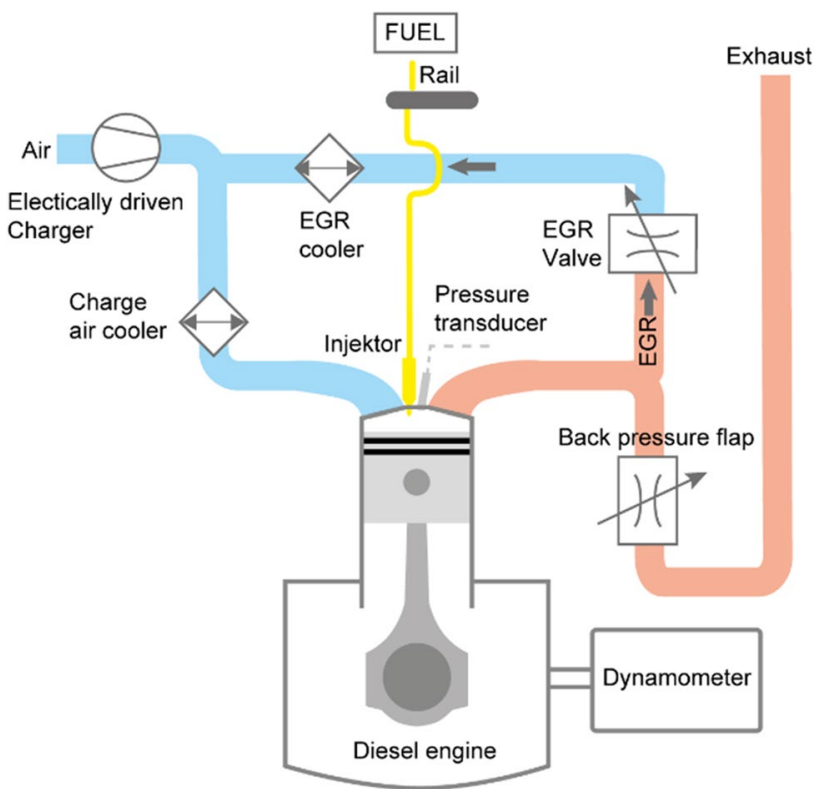

Fig. 4 Schematic layout of the test bench 
The investigations are carried out at two operating points at the Institute for Powertrains and Automotive Technology at the Vienna University of Technology. The first point is defined by an engine load of 5 bar indicated mean effective pressure at $1500 \mathrm{rpm}$, the second -15 bar indicated mean effective pressure also at $1500 \mathrm{rpm}$; see Table 3. Variations of the air-fuel ratio, the EGR rate and the MFB50\% (by adjusting the start of injection) are carried out. The difference between intake and exhaust pressure (negative scavenging pressure) is held constant through the variations, however, depending on the load point. This way the effect of the gas exchange on the indicated efficiency is being isolated and the influence of other combustion parameters can be better observed. The results of the variations are analysed and the optimum operating parameters for the respective fuel are determined. The pure diesel operation is the reference for the comparison. In order to create boundary conditions for the fuel comparison, an upper limit for NOx emissions of $2 \mathrm{~g} /$ $\mathrm{kWh}$ is set. The maximum intake manifold pressure is limited to 2250 mbar (abs.). The first tests with pure OMEmix imposed the necessity of increasing the injection pressure at the higher load point, since operating at the same pressure as with diesel resulted in very long injection durations due to the significantly lower lower heating value of OMEmix. All specific emission values in this study are with respect to indicated engine work.

\section{Results of the combustion investigations}

\subsection{Dibutyl ether}

\subsubsection{Soot and particle emissions (DBE)}

The most effective measure for the in-cylinder reduction of the nitrogen oxide emissions is the increase of the EGR rate. In case of conventional diesel fuel, this leads to an increase of soot emissions, so that a compromise must be made when designing the operating parameters. According to literature, DBE is expected to show advantageous properties for

Table 3 Investigated operating points with engine parameters

\begin{tabular}{lll}
\hline Load point notation & OP-1500/5 & OP-1500/15 \\
\hline Speed (rpm) & 1500 & 1500 \\
$p_{\text {mi }}$ (bar) & 5 & 15 \\
Rail pressure (bar) & $\sim 670$ & $\sim 1000$ \\
& & $(1200+$ for \\
& & pure OMEmix) \\
Injection pattern & Single injection & Single injection \\
Intake manifold pressure (mbar) & variable & 2250 \\
$\Delta$ pressure exhaust-intake (mbar) & 270 & 500 \\
\hline
\end{tabular}

reducing soot and particle number in the combustion process of the diesel engine due to its oxygen content, absence of double bonds between the carbon atoms and enhanced spray formation. Starting with the lower load point, the specific soot emissions of DBE and a blend of diesel and 20\% DBE are compared to the results of diesel reference operation by means of a variation of the exhaust gas recirculation rate (EGR rate). Figure 5 displays the findings.

For each of the three fuels about $20 \%$ EGR is needed in order to lower the NOx emissions under the set limit of $2 \mathrm{~g} / \mathrm{kWh}$. However, no significant soot production occurs before $30 \%$ EGR. It is visible that the soot mass emissions of neat DBE operation remain lower in comparison to diesel and at $50 \%$ EGR the reduction is more than $40 \%$. Nevertheless, the effect is not as strong as expected. Furthermore, the exhaust gas in blend operation shows a remarkably higher soot mass content than reference operation. The behaviour of

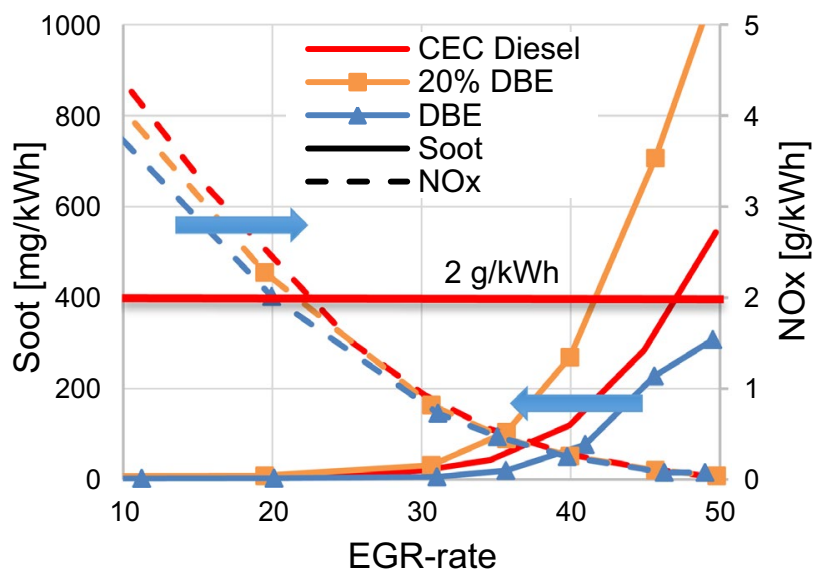

Fig. 5 Soot mass and nitrogen oxides at OP-1500/5; variation of EGR rate, intake manifold pressure const. 1130 mbar; MFB50\% $7.5^{\circ} \mathrm{CAaTDC}$

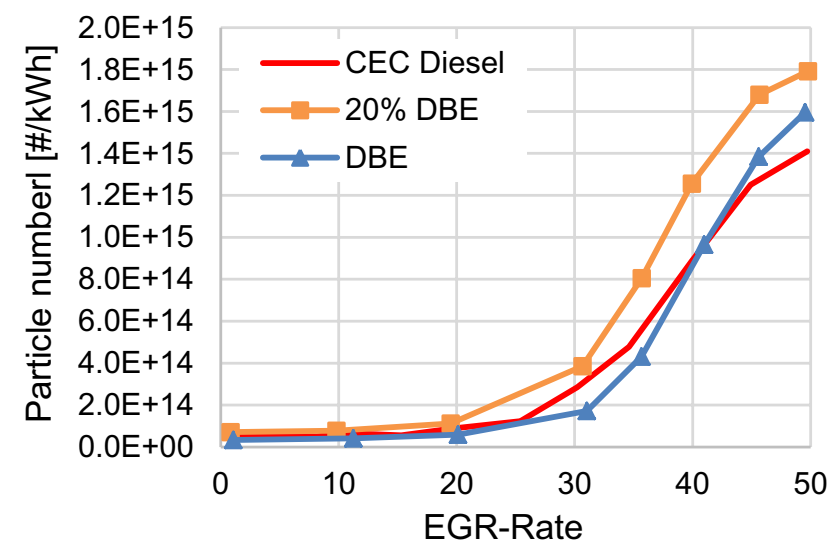

Fig. 6 Particle number at OP-1500/5; variation of EGR rate, intake manifold pressure const. 1130 mbar; MFB50\% $7.5^{\circ} \mathrm{CAaTDC}$ 
the particle number over a variation of EGR rate is shown in Fig. 6. In this case the particle count of neat DBE and diesel are almost equal (within a repeatability tolerance) and the blend produces slightly more particles.

Both figures lead to the assumption that since particle number in blend operation does not exceed the diesel reference value with the same factor as soot mass emissions do, the particles must be bigger and heavier than in diesel reference operation. At first these results look surprising, however, the influence of the very high ignitability of DBE should not be underestimated. The add-on of $20 \%$ DBE to diesel shortens the duration between the start of injection and the start of combustion, also called ignition delay, as Fig. 7 proves. This effect is very pronounced for neat DBE. Interesting in this matter is also the duration between the end of injection and the start of combustion. It is the longest in the case of diesel and the shortest for DBE. Figure 8 displays these relations in a quantitative manner.

The reaction zone of a diesel fuel jet stabilizes at a location downstream of the fuel injector once the initial autoignition phase is over. This distance is referred to as flame liftoff length [46]. The short ignition delay of neat DBE reduces the lift-off length and leaves less time for spray evaporation, thus more locally fuel rich zones and more diffusive combustion occur. Due to the advantageous properties of the DBE molecule, the negative effect of the high cetane number on soot production is compensated, as can be seen in Fig. 6 for the lower load point. Adding only $20 \%$ DBE to the diesel fuel on the other hand has a very negative impact on soot and particle production, because the DBE fraction of the fuel autoignites earlier and consequently ignites the diesel portion. The ignition delay is shortened compared to pure diesel and less premixed combustion takes place (see Fig. 7), therefore the emissions rise.

For the observations of the higher load point (OP$1500 / 15)$, the NOx limit of $2 \mathrm{~g} / \mathrm{kWh}$ represents a real

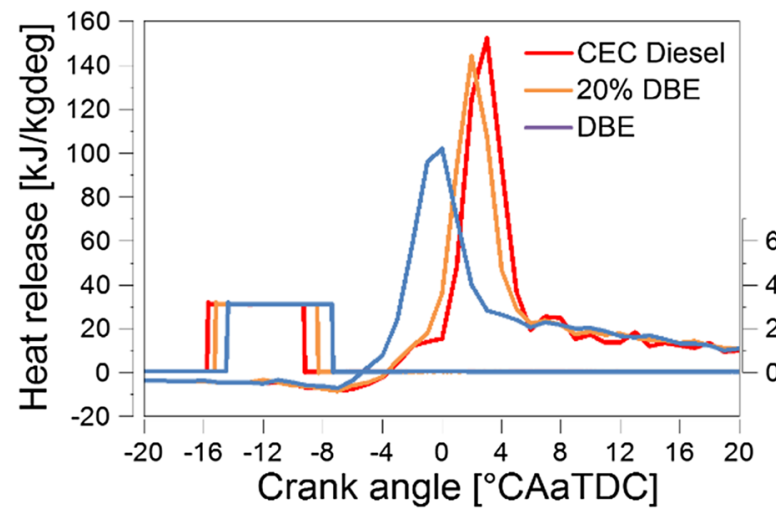

Fig. 7 Injection timing and heat release rate at OP-1500/5; intake manifold pressure const. 1130 mbar; MFB50\% $7.5{ }^{\circ} \mathrm{CAaTDC}, 45 \%$ EGR

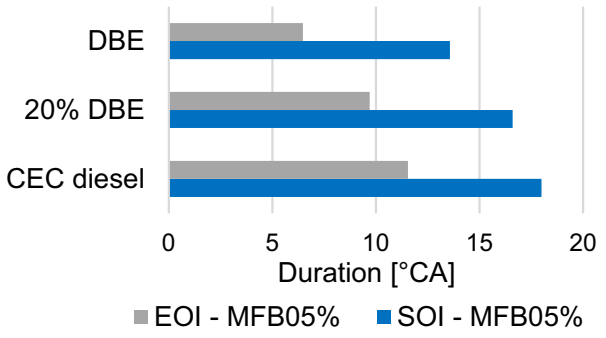

Fig. 8 Duration from start/end of injection to combustion beginning MFB05\%; intake manifold pressure const. 1130 mbar; MFB50\% $7.5^{\circ} \mathrm{CAaTDC}, 45 \%$ EGR

constraint. In order to fulfil this requirement, a high EGR rate or a delayed centre of combustion is needed. The investigations proved that the second measure is preferable, since increasing the EGR rate effects a stronger emission rise and efficiency deterioration than retarding the ignition timing. Figure 9 shows the development of soot mass and particle number emissions for diesel, 20\% DBE and neat DBE over a variation of the centre of combustion at higher load. To reach the target of highest possible efficiency under the mentioned boundary conditions, $15 \%$ EGR and a MFB50\% of $12.5{ }^{\circ} \mathrm{CAaTDC}$ are needed here. Lambda value is $1.25-1.3$ and soot and particle production are enhanced in comparison to the lower load point OP-1500/5.

At higher load the fuel injection duration is longer and ignition and combustion begin before the end of injection. Therefore, the flame front is much closer to the injector nozzle. Due to high fuel and burnt gas amount the locally rich combustion zones are more and the high combustion temperatures also lead to pyrolysis of fuel droplets. All these aspects account for increased soot emission levels. Because

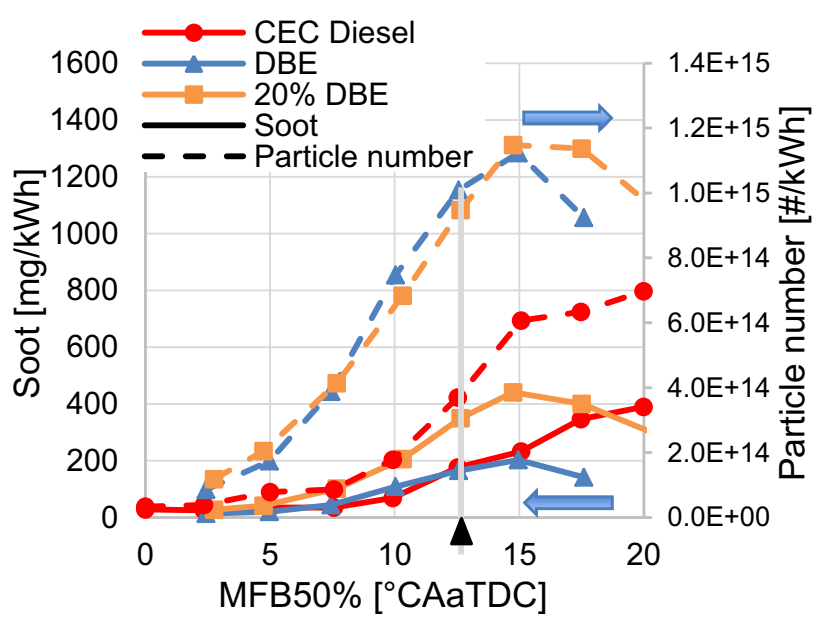

Fig. 9 Soot mass and particle number at OP-1500/15; variation of combustion center MFB50\%, 15\% EGR; NO $x$ emissions $\leq 2 \mathrm{~g} / \mathrm{kWh}$ at MFB50\% $12.5^{\circ} \mathrm{CAaTDC}$ 


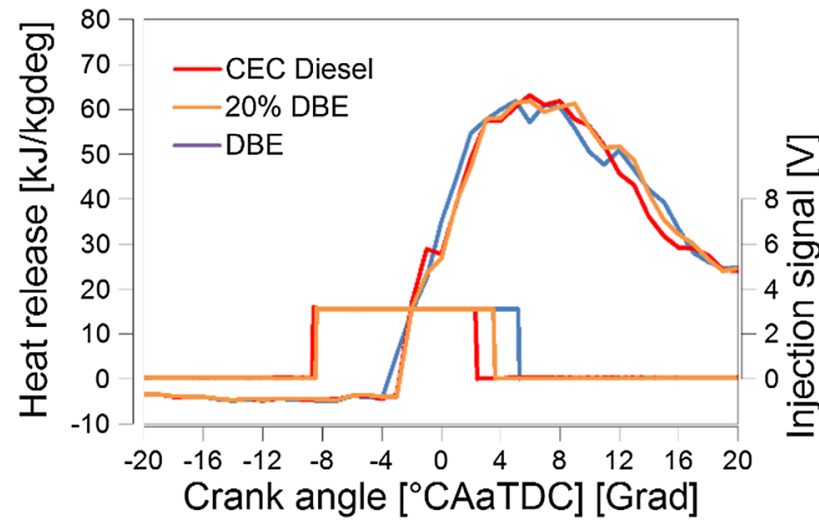

Fig. 10 Injection timing and heat release rate at OP-1500/15; MFB50\% $12.5{ }^{\circ} \mathrm{CAaTDC}, 15 \% \mathrm{EGR}$

of the reduced lower heating value of DBE in regard to diesel, the injection of the highly ignitable ether takes even longer, which means that a larger amount of the fuel is injected into a burning flame zone; see Fig. 10.

As a result DBE does not improve the soot emissions of the diesel engine at the tested load point. According to the explanations of the behaviour at OP-1500/5, 20\% DBE increases the soot mass output also at OP-1500/15.

Particle number emissions of DBE and 20\% DBE are similar and more than twice higher than at neat diesel operation. To properly explain this enormous increase in particle count a detailed analysis of the spray and droplet formation is needed. However, it can be concluded from Fig. 9 that in contrast to the lower load point the particles at DBE and $20 \%$ DBE operation must be smaller and/or lighter than the particles originating from diesel.

\subsubsection{Efficiency (DBE)}

In terms of efficiency no significant differences are measured between the three fuels. At higher load the percentage share

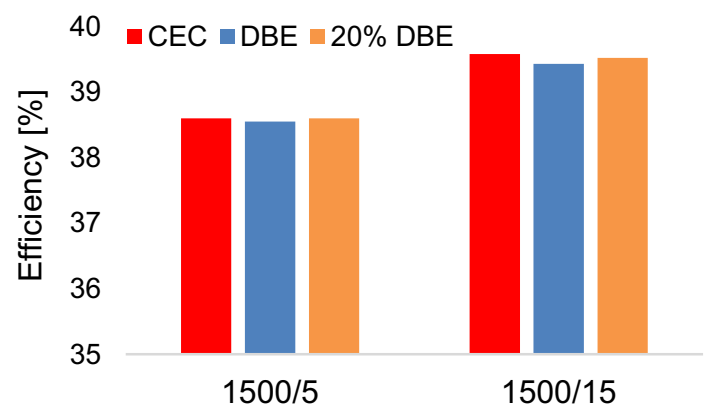

Fig. 11 Maximum engine efficiency for both load points under a limit consideration of $\mathrm{NO} x \leq 2 \mathrm{~g} / \mathrm{kWh}$ of wall heat loss is less, which adds to the higher efficiency value of $1 \%$ point, as displayed in Fig. 11.

\subsection{Oxymethylene ether}

\subsubsection{Soot and particle emissions (OMEmix)}

Figure 12 shows the soot-NO $x$ trade-off for the CEC diesel reference in BP-1500/5 and compares it with the behaviour of the diesel-OMEmix fuel blend and the operation with OMEmix.

The rise in soot mass emissions is profound in the case of diesel for EGR rates higher than 35\%. Blending the fuel with $20 \mathrm{vol} \%$ OMEmix proves a soot reduction effect of about $50 \%$ at a NOx emission value of $0.25 \mathrm{~g} / \mathrm{kWh}$. The advantage is obvious even at higher EGR rates and allows using higher amounts of recirculated exhaust gases in order to achieve further reduction of nitrogen oxides, without exceeding given soot limits. It is also to be mentioned that at the same EGR rates operation with 20\% OMEmix emits less nitrogen oxides. As expected, the soot-NO $x$ trade-off is completely eliminated when using neat OMEmix. For this fuel the soot emissions remain below $0.1 \mathrm{mg} / \mathrm{kWh}$ even at $50 \%$ EGR, which results in an approximate $\lambda$ value of 1.2 .

The dependence of the particle number on the EGR rate reveals that the addition of 20 vol\% OMEmix to diesel does not provide the same emission reduction effect as on soot mass. The particle number is almost unchanged by blending with OMEmix [20] (not shown here), which correlates with the results with the other ether DBE (Fig. 6). In the diesel-OMEmix blend diesel still accounts for about $87 \%$ of the energy content in the fuel. Since OMEmix burns "soot free" and additionally provides oxygen in the flame that can quickly react with the diesel molecules, the soot mass is reduced. However, the measurements suggest that

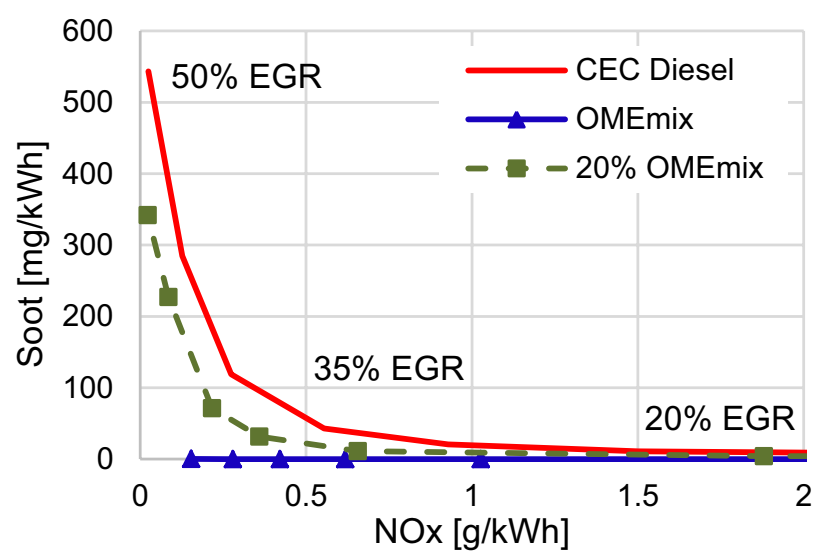

Fig. 12 Soot-NO $x$ trade-off at OP-1500/5; variation of EGR rate; intake manifold pressure const. $1130 \mathrm{mbar}$, MFB50\% $7.5{ }^{\circ} \mathrm{CAaTDC}$ [20] 
blend operation emits finer particles, since their number is not noticeably reduced. The origin of these particles must lie in the diesel fuel, as the neat oxymethylene ether substances do not produce any significant particle emissions. The same trend of reducing soot emissions while having no significant influence on particle count is reported in literature with a blend of diesel and 25\% OME1 [14].

Pure OMEmix on the other hand shows extremely low particle number-even at 50\% EGR the value is in the range of $2 \times 10^{11}$ particles per $\mathrm{kWh}$ or $5 \times 10^{4}$ particles per $\mathrm{cm}^{3}$ [20]. For comparison, at this point diesel is measured to produce $1.4 \times 10^{15}$ particles per $\mathrm{kWh}$ or $2.7 \times 10^{8}$ particles per $\mathrm{cm}^{3}$.

At the higher load point OP-1500/15 no soot mass reduction is measured when operating with the $20 \mathrm{vol} \%$ oxymethylene blend; see Fig. 13. Particle number is very similar for both diesel reference and blend fuel (not shown here, [20]). Nevertheless, the superior qualities of neat OMEmix are present at higher loads as well. Soot mass and particle number are even further reduced with increasing EGR rate. The reason for this phenomenon is assumed to be the $70{ }^{\circ} \mathrm{C}$ drop of combustion temperature (from 0\% EGR to $20 \%$ EGR, calculated in a separate combustion analysis) and an associated reduction of soot formation. At neat OMEmix operation with $20 \%$ EGR lambda is 1.2 , soot mass is below $1 \mathrm{mg} / \mathrm{kWh}$ and particle number is measured to be $1 \times 10^{12}$ particles per $\mathrm{kWh}$ or $1 \times 10^{5}$ particles per $\mathrm{cm}^{3}$ [20]. These values are still in the range of pollution concentration of ambient air in big cities $[15,49]$ and are achieved without any exhaust gas aftertreatment.

The results displayed in Fig. 13 show that the emissions of nitrogen oxides at OME operation are not reduced in the same way as in reference or blend operation. The analysis of the indicated data of the operation point with $20 \%$ EGR revealed that despite equal maximum cylinder temperature,

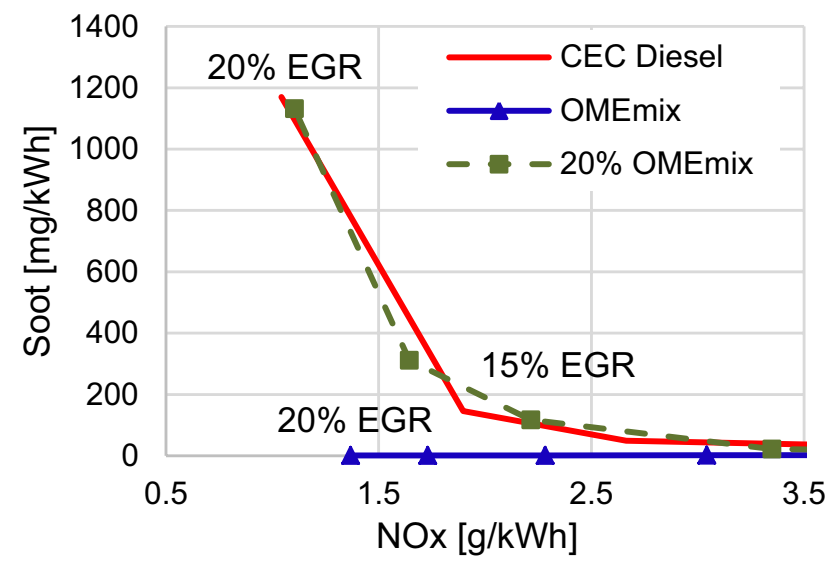

Fig. 13 Soot-NOx trade-off at OP-1500/15; variation of EGR rate; intake manifold pressure const. 2250 mbar, MFB50\% $7.5{ }^{\circ} \mathrm{CAaTDC}$ [20] in the case of OMEmix high temperatures are longer present on a time scale than with pure diesel. Therefore, more time is available for NO to form. Additionally, combustion of the OMEmix presented here requires less air and more air remains unreacted at constant intake manifold pressure. As a consequence, the lambda value is higher for OMEmix (1.2 at 20\% EGR and 2250 mbar intake manifold pressure) than for diesel or the blend (1.1 at 20\% EGR and 2250 mbar intake manifold pressure) and more oxygen can react to NO. For both reasons NO $x$ emissions are higher for OMEmix operation than for diesel at the same EGR rate. It is logical to further increase the EGR rate in OMEmix operation; however, combustion quality downgrades.

Figure 14 compares the soot concentration and particle number in the exhaust gas of engine operation with OMEmix with the according concentrations in the laboratory ambient air. Compared to OP-1500/5, the values of OP-1500/15 are higher, but it should also be mentioned that the effect of the motor oil cannot be separated, since the oil used is not ash-free.

\subsubsection{Efficiency and combustion analysis (OMEmix)}

The thermodynamic analysis of the low load point operation OP-1500/5 revealed no difference in combustion between diesel, diesel-OMEmix blend or neat OMEmix. The different fuels, however, required an adjustment of the injection timing, in order to achieve the same MFB50\%. The indicated efficiency is measured to be $38.5 \%$ and is barely affected by an increase in the EGR rate until reaching $45 \%$ EGR. At $50 \%$ EGR the lambda value is 1.2 and efficiency decreases.

At OP-1500/15 the limit set for nitrogen oxide emissions leads to efficiency values that are significantly lower than the theoretically possible combustion efficiency if NOx emissions were not taken into account. The way the indicated efficiency changes with increasing the EGR rate is shown in

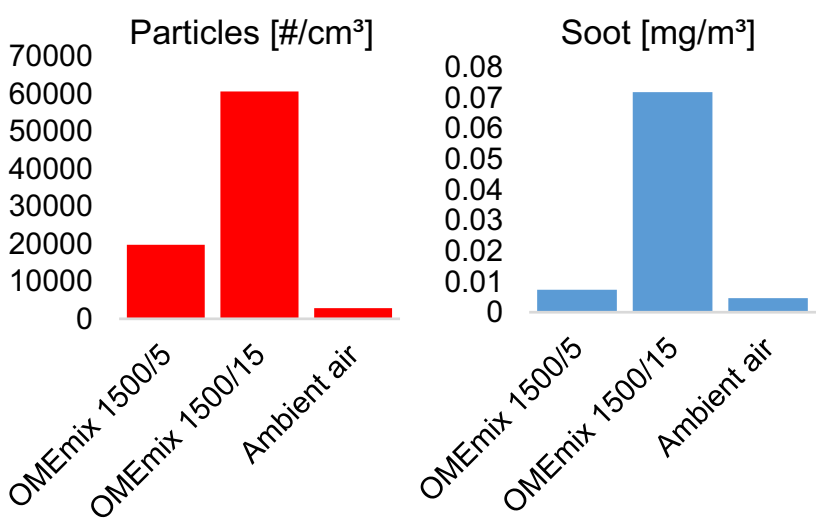

Fig. 14 Comparison of soot mass and particle number concentrations in OMEmix operation at both load points with laboratory ambient air concentration values 


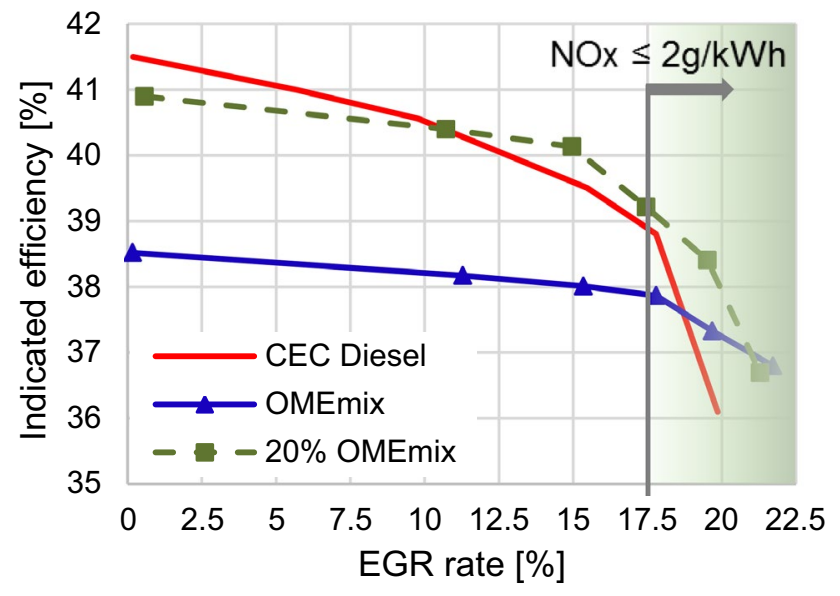

Fig. 15 Indicated efficiency as a function of EGR rate at OP-1500/15; intake manifold pressure const. 2250 mbar, MFB50\% $7.5{ }^{\circ} \mathrm{CAaTDC}$ [20]

Fig. 15. The OMEmix blend shows higher tolerance against high amounts of recirculated exhaust gas than diesel; however, its efficiency is comparable to the efficiency of diesel reference operation. The efficiency of operation with neat OMEmix is at a lower level until 20\% EGR, but it does not decrease the same way as with other fuels when raising the EGR rate. For this reason, the difference to the efficiency of diesel reference at $2 \mathrm{~g} / \mathrm{kWh} \mathrm{NO} x$ is noticeably reduced.

As seen in Fig. 13, operation with 17.5\% EGR at high load produces much more soot emissions than with $15 \%$ EGR.

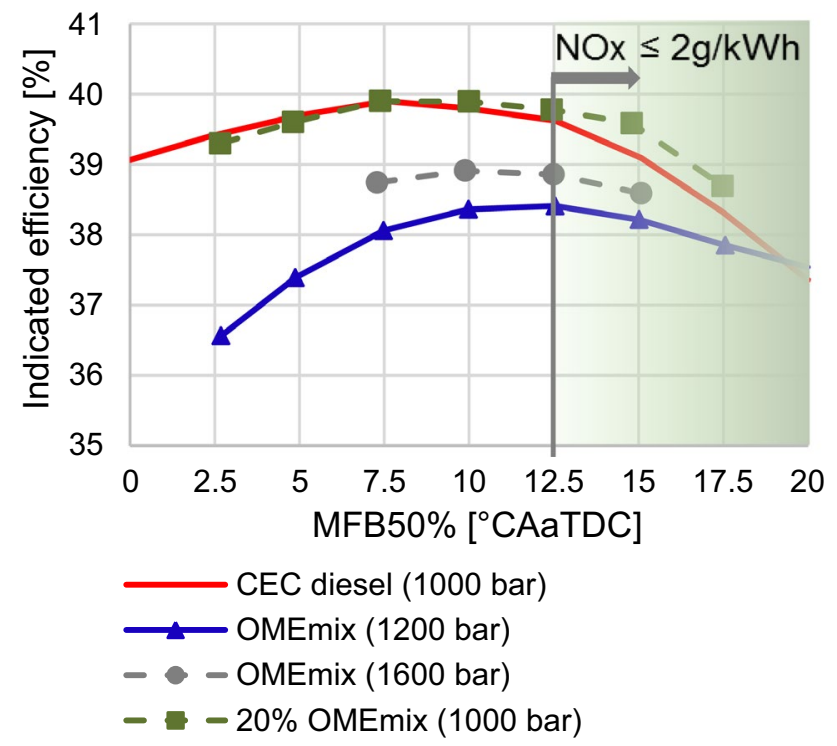

Fig. 16 Indicated efficiency as a function of combustion centre MFB50\% at OP-1500/15; intake manifold pressure const. 2250 mbar, $15 \%$ EGR [20]
The efficiency plots in Fig. 16 prove that operation with $15 \%$ EGR and MFB50\% $12.5{ }^{\circ} \mathrm{CAaTDC}$ is preferable to operation with 17.5\% EGR and MFB50\% $7.5^{\circ} \mathrm{CAaTDC}$ (see correspondent indicated efficiency in Fig. 15).

Figure 16 visualizes that there is no efficiency difference between diesel and the diesel-OMEmix blend. It is also shown that the efficiency of neat OMEmix operation lies almost $2 \%$ points below the reference values. Due to the much lower lower heating value of OME compared to diesel, the fuel injection takes more time and results in an extended duration of the main combustion, which decreases the thermodynamic efficiency. The injection pressure was chosen to be 1200 bar for the investigations with neat OMEmix (for comparison diesel is injected with 1000 bar), in order to reduce the injection duration. This step, however, was not sufficient to achieve the desired result. By further increasing the injection pressure a part of this drawback can be compensated, as exemplarily shown for OMEmix at 1600 bar injection pressure, but diesel efficiency cannot be completely matched.

In contradiction to the common case and to the diesel reference results, at neat OMEmix operation with $1200 \mathrm{bar}$ injection pressure the position of maximum efficiency MFB50\% is not in the range of $7-10{ }^{\circ} \mathrm{CAaTDC}$ but is moved to later values. As can be seen from the indicated data in Fig. 17, a bigger part of OMEmix combustion takes places before the piston reaches TDC if injection pressure

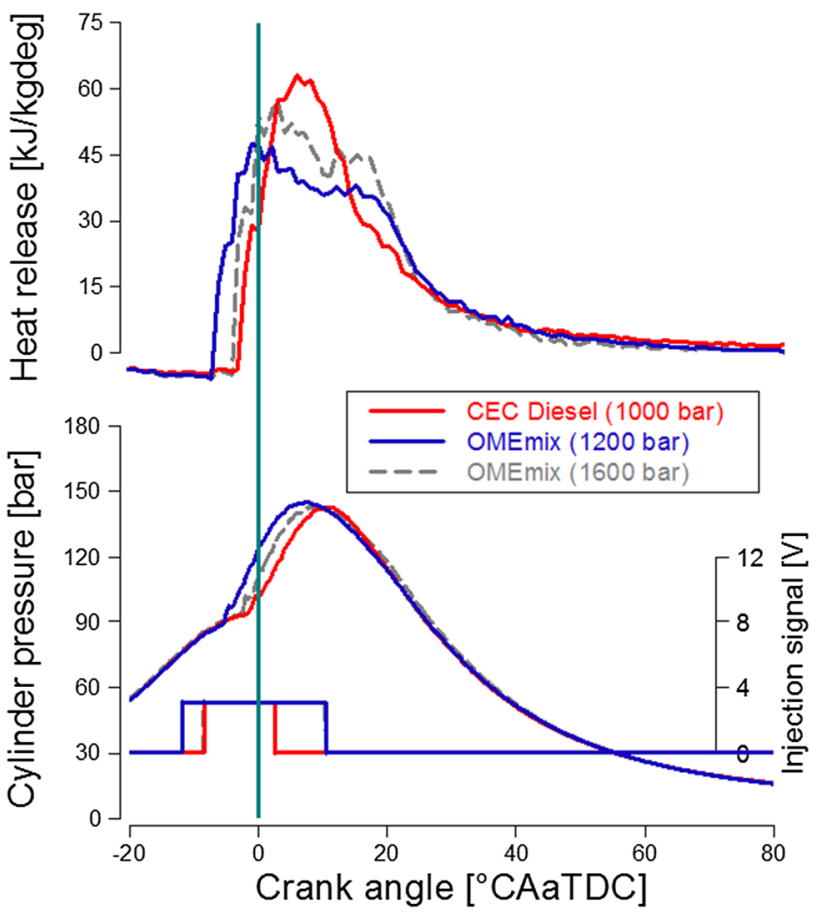

Fig. 17 Comparison of indicated data at OP-1500/15; $15 \%$ EGR; MFB50\% $12.5^{\circ} \mathrm{CAaTDC}$ 
Table 4 Comparison of the results via characteristic numbers at OP-1500/15, maximal efficiency under the limit considerations of $\mathrm{NO} x \leq 2 \mathrm{~g} / \mathrm{kWh}$ and intake manifold pressure of $2250 \mathrm{mbar}$

\begin{tabular}{lclllrr}
\hline Fuel (combination) & $\begin{array}{l}\text { Engine } \\
\text { efficiency }\end{array}$ & $\begin{array}{l}\text { Fuel } \mathrm{CO}_{2} \text { eq/ } \\
\text { energy unit }\end{array}$ & $\begin{array}{l}\mathrm{CO}_{2} \text { (well-to- } \\
\text { wheel) }\end{array}$ & $\begin{array}{l}\mathrm{CO}_{2} \text { (tank-to- } \\
\text { wheel) }\end{array}$ & PM & PM\# \\
\hline CEC diesel & 100 & 100 & 100 & 100 & 100 & 100 \\
DBE & 99 & 33 & 34 & 101 & 93 & 273 \\
$20 \%$ DBE & 100 & 90 & 90 & 101 & 198 & 256 \\
OMEmix & 97 & 29 & 30 & 114 & 0 & 0 \\
$20 \%$ OMEmix & 100 & 91 & 91 & 101 & 63 & 141 \\
\hline
\end{tabular}

is not adjusted. This inevitably leads to higher thermodynamic losses, especially as a consequence of blowby and increased wall heat losses, which are the highest at TDC. For this reason moving MFB50\% to a later position of approx. $12.5^{\circ} \mathrm{CAaTDC}$ is favourable from an efficiency point of view. It can be seen in Fig. 17, the diesel reference has a more compact main combustion phase, followed by OMEmix with 1600 bar injection pressure. OMEmix at 1200 bar injection pressure shows a longer main combustion phase that also starts too early. These findings lead to the assumption that if the flowrate of the injection system is adequately adapted, the same efficiency as in operation with CEC diesel could be reached with OMEmix without the need of increasing injection pressure, which also increases mechanical losses. This expectation has recently been proven in [50].

\section{Comparative analysis}

The insights gained from the engine studies clearly show the trends that can be expected when using the investigated fuels. In order to be able to compare their advantages and disadvantages for diesel engine use in a quantitative manner, a direct comparison of the results is useful. For this purpose, the optimal operation parameter settings for all fuels at $1500 / 15$ are depicted.

The overall assessment of the biofuel use is based both on the consideration of the combustion engine suitability and on the fuel production criteria. The assessed categories are engine efficiency, well-to-wheel and tank-to-wheel $\mathrm{CO}_{2}$ emissions, particle mass and count. For a clearer presentation of the evaluation, characteristic numbers are defined, which represent the percentage change towards the diesel reference values. The diesel reference is given the number 100 , e.g. a $3 \%$ improvement in engine efficiency when using a biofuel would get the number 103, a deterioration of the same value 97 .

The $\mathrm{CO}_{2}$ savings potential for biofuel production is determined within the framework of the production analysis and is described as " $\mathrm{CO}_{2}$ /energy unit". It is included in the " $\mathrm{CO}_{2}$ (well-to-wheel)" criterion. Thus, the $\mathrm{CO}_{2}$ advantage increases with the substitution rate. The $\mathrm{CO}_{2}$ savings in the production of oxymethylene ether from lignocellulosic biomass are assumed to be $71 \%$, and for DBE $67 \%$ (as can be seen in Table 2). An emission characteristic number of 34, e.g. means that the emissions add up to only $34 \%$ of the CEC diesel reference emissions.

Table 4 summarizes the evaluation of the best adapted parameter settings for each of the fuels. Significant potentials of the use of biogenic oxymethylene ethers and dibutyl ether in the diesel engine are visible. For example, by operation with DBE $66 \%$ well-to-wheel $\mathrm{CO}_{2}$ is saved. The greenhouse gas savings with OMEmix are $70 \%$ and the particle mass in the exhaust gas is reduced to approx. $0 \%$ of the particle mass emissions of the diesel reference operation, which makes a reduction of almost $100 \%$. Substituting 20 vol $\%$ of the conventional diesel with OMEmix helps emit $9 \%$ less $\mathrm{CO}_{2}$ and $37 \%$ less soot, at low load the improvement is even higher. Unfortunately, a rise in particle number compared to diesel is measured with the blends. Emissions of soot mass and particle number can be reduced to ambient air levels by using neat OME. This way soot emissions are no longer a constraint in engine application and the exhaust gas recirculation rate is only restricted by efficiency concerns and possible methane emissions at stoichiometric operation. The $14 \%$ rise in tank-to-wheel $\mathrm{CO}_{2}$ emissions at OMEmix operation is a result of the ratio of the fuel carbon content to its heating value and gets higher with a higher OME fraction in the fuel blend. However, it must be noticed that for future biofuel applications and related greenhouse gas assessment not solely the tank-to-wheel balance, but the holistic well-towheel calculation of the carbon footprint must be observed.

\section{Conclusion and outlook}

This study investigates the diesel engine suitability of two alternative diesel fuels-dibutyl ether and oxymethylene ether-and describes pathways for their production. The results of the production simulation are evaluated and combined with the engine tests findings. Manufacturing of both fuels requires high amounts of biomass and high investment costs, the process costs, however, are acceptable. An important advantage of the tested fuels is the potential to produce them as second generation biofuels, which considerably mitigates the ethical dispute on the competition between fuel and food production. Both dibutyl ether and oxymethylene 
ether show good performance in the used diesel engine. By optimizing the injection system for fuels with low lower heating value, possible efficiency drawbacks can be compensated. Soot and particle emissions can be reduced to an extreme extent by using neat oxymethylene ethers and in this case the classical soot-NOx trade-off is being eliminated. Dibutyl ether usage on the other hand could not effectively decrease soot emissions. Nevertheless, both fuels offer significant greenhouse gas reduction potentials by up to $70 \%$.

Detailed research is needed to explain the discrepancy between the soot and particle emissions of dibutyl ether in this work and the findings reported in the quoted literature. The impact of the additivation with the lubricant monocarboxylic acid on the soot emissions is to be checked. Additionally, it is interesting to understand the rise in particle number when using both investigated blends. Comprehensive examination of spray formation and break-up will be helpful on this issue.

Acknowledgements Open access funding provided by TU Wien (TUW). Special thanks to the Austrian Ministry for Transport, Innovation and Technology (BMVIT) for financially supporting this project within the Future Mobility Program. We would also like to thank our partners, especially the employees involved in the project at AVL List $\mathrm{GmbH}$, Institute of Chemical Engineering and Environmental Technology at the Graz University of Technology and OMV Refining \& Marketing $\mathrm{GmbH}$.

Open Access This article is distributed under the terms of the Creative Commons Attribution 4.0 International License (http://creativeco mmons.org/licenses/by/4.0/), which permits unrestricted use, distribution, and reproduction in any medium, provided you give appropriate credit to the original author(s) and the source, provide a link to the Creative Commons license, and indicate if changes were made.

\section{References}

1. Eurostat: Greenhouse gas emission statistics-emission inventories (2017) Online article. http://ec.europa.eu/eurostat/stati stics-explained/index.php/Greenhouse_gas_emission_statistics. Accessed 13 June 2017

2. Schwaiger, N.: Lignozellulose basierte sauerstoffhaltige Dieselersatzkraftstoffe; Study; Technische Universität Graz, Institut für chemische Verfahrenstechnik und Umwelttechnik; März 2015, Graz, Austria (2015)

3. Pischinger, S., Hoppe, F., Krieck, M., Budak, O., Zubel, M., Graziano, B., Heuser, B., Kremer, F.: Fuel design for future combustion engines-a view from the cluster "Tailor-Made Fuels from Biomass"; Lenz (Hrsg.); ISBN 978-3-18-379912-1; 37. Internationales Wiener Motorensymposium, 28-29 April 2016, Vienna (2016)

4. Janssen, A., Kremer, F., Baron, H., Muether, M., Pischinger, S., Klankermayer, J.: Tailor-made fuels from biomass for homogeneous low-temperature diesel combustion. Energy Fuels 25, 47344744 (2011). https://doi.org/10.1021/ef2010139

5. Graziano, B., Jakob, M., Kremer, F., Pischinger, S., Lee, C., Fernandes, R.: Investigation on the ignition sensitivity of 2-MTHF, heptane and di-n-butylether. In: Proceedings of the 6th European
Combustion Meeting; 25th to 28th of June, 2013; Lund, University, Sweden (2013)

6. Kremer, F., Heuser, B., Pischinger, S., Klankermayer, J.: Optimizing diesel combustion behaviour with tailor-made fuels from biomass. In: Proceedings of the 9th International Colloquium Fuels 15th to 17th of January 2013, Ostfildern (2013)

7. Janssen, A., Jakob, M., Muether, Pischinger, S., Klankermayer, J.: Tailor-made fuels from biomass for partly homogenous low temperature combustion systems. In: Proceedings of the 20th Aachen Colloquium Automobile and Engine Technology, Aachen (2011)

8. Pischinger, S., Kremer, F., Hoppe, F., Heuser, B.: Fuel as a design parameter for future low emission engines. In: JSAE/SAE Powertrains, Fuels \& Lubricants Meeting, Conference, Kyoto Japan, September (2015)

9. Heuser, B., Jakob, M., Kremer, F., Pischinger, S., Kerschgens, B., Pitsch, H.: Tailor-made fuels from biomass: influence of molecular structures on the exhaust gas emissions of compression ignition engines (No. 2013-36-0571). SAE Technical Paper (2013)

10. Boot, M.: Biofuels from Lignocellulosic Biomass. Innovations beyond Bioethanol. Wiley-VCH Verlag GmbH \& Co. (2016) (ISBN: 978-3-527-33813-9)

11. Beeckmann, J., Aye, M., Gehmlich, R., Peters, N.: Experimental investigation of the spray characteristics of dI-n-butyl ether (DNBE) as an oxygenated compound in diesel fuel; SAE paper 2010-01-1502; ISSN 0148-7191; https://doi. org/10.4271/2010-01-1502

12. Härtl, M., Gaukel, K., Pelerin, D., Wachtmeister, G.: Oxymethylenether als potenziell $\mathrm{CO}_{2}$-neutraler Kraftstoff für saubere Dieselmotoren. Teil 1: MotoruntersuchungenMTZ Motortechnische Zeitschrift 02/2017, 78. Jahrgang, p. 52-58

13. Gaukel, K., Pelerin, D., Härtl, M., Wachtmeister, G., Burger, J., Maus, W., Jacob, E.: The fuel OME2: an example to pave the way to emission-neutral vehicles with internal combustion enginelenz (Hrsg.) ISBN 978-3-18-379912-137. Internationales Wiener Motorensymposium, 28-29 April 2016, Vienna (2016)

14. Härtl, M., Seidenspinner, P., Jacob, E., Wachtmeister, G.: Oxygenate screening on a heavy-duty diesel engine and emission characteristics of highly oxygenated oxymethylene ether fuel $\mathrm{OME}_{1}$. Fuel J. 153 328-335 (2015). https://doi.org/10.1016/j. fuel.2015.03.012

15. Pellegrini, L., Marchionna, M., Patrini, R., Beatrice, C., Del Giacomo, N., Guido, C.: Combustion behaviour and emission performance of neat and blended polyoxymethylene dimethyl ethers in a light-duty diesel engine SAE 2012-01-1053

16. Lumpp, B., Rothe, D., Pastötter, C., Lämmermann, R., Jacob, E.: Oxymethylenether als Dieselkraftstoffzusätze der Zukunft MTZ Motortechnische Zeitschrift 03/2011, 72. Jahrgang, pp. 198-202

17. Härtl, M., Seidenspinner, P., Wachtmeister, G., Jacob, E.: Synthetischer Dieselkraftstoff OME1-Lösungsansatz für den Zielkonflikt NOx-/Partikel-Emission MTZ Motortechnische Zeitschrift 07-08/2014, 75. Jahrgang, pp. 68-73

18. Feiling, A., Münz, M., Beidl, C.: Potential of the synthetic fuel OME1b for the soot-free diesel Engine MTZextra; fuels and lubricants of the future, pp. 16-21 (2016)

19. Richter, G., Zellbeck, H.: OME als Kraftstoffersatz im PkwDieselmotor; MTZ Motortechnische Zeitschrift 12/2017, 78. Jahrgang, pp. 66-72

20. Damyanov, A., Hofmann, P., Drack, J., Pichler, T., Schwaiger, N., Siebenhofer, M.: Operation of a diesel engine with biogenous oxymethylene ethers. In: Proceedings of the 26th Aachen Colloquium Automobile and Technology, pp. 289-314 (2017)

21. Richtlinie: 2009/28/EG des Europäischen Parlaments und des Rates vom 23. April 2009 zur Förderung der Nutzung von Energie aus erneuerbaren Quellen und zur Änderung und anschließenden 
Aufhebung der Richtlinien 2001/77/EG und 2003/30/ EG.Amtsblatt der Europäischen Union L 140/16, 5.6.2009 (2009)

22. Crusius, S., Müller, M., Stein, H.: Oxy-methylen-di-methylether (OMDME or OMEx) as an alternative for diesel fuel: properties, additivation and first engine tests nikolai schubert (Hrsg.). In: Proceedings of the 11th International Colloquium Fuels; Ostfildern, June 27-29, (2017)

23. Damyanov, A., Hofmann, P., Derntl, M., Schüßler, M., Pichler, T., Schwaiger, N., Siebenhofer, M.: Regenerative oxygen-containing diesel substitute fuels as an ecological option for increasing efficiency and minimizing emissions; nikolai schubert (Hrsg.). In: Proceedings of the 11th International Colloquium Fuels; Ostfildern, June 27-29, (2017)

24. Humbird, D., Davis, R., Tao, L., Kinchin, C., Hsu, D., Aden, A.: Process design and economics for biochemical conversion of lignocellulosic biomass to ethanol. Renew. Energy 303, 147 (2011)

25. Alriols, M.G., García, a, Llano-ponte, R., Labidi, J.: Combined organosolv and ultrafiltration lignocellulosic biorefinery process. Chem. Eng. J. 157(1), 113-120 (2010)

26. BioGrace-harmonised calculations of biofuel greenhouse gas emissions in Europe. [Online] (2015). http://www.biograce.net/. Accessed 13 Apr 2015

27. Pichler, T.: Simulation und bewertung der herstellung von sauerstoffhaltigen dieselersatzkraftstoffen aus zellulose und hemizellulose", Diplomarbeit, Graz University of Technology, (2016)

28. Berteau, P., Delmon, B.: Modified aluminas: relationship between activity in 1-butanol dehydration and acidity measured by $\mathrm{NH}_{3}$ TPD. Catalysis Today 5, 121-137 (1989)

29. Ströfer, E., Hasse, H., Schelling, H., Blagov, S.: Method for the production of polyoxymethylene dialkyl ethers from trioxan and dialkylethers. Patent (US7999140); 12.06.2006 (2006)

30. Schelling, H., Ströfer, E., Pinkos, R., Haunert, A., Tebben, G.D., Hasse, H., Blagov, S.: Method for producing polyoxymethylene dimethyl ethers. Patent (WO 2006045506); 19.10.2005 (2005)

31. Ströfer, E., Sinnen, R., Schweers, O., Thiel, J., Hasse, H., Siegert, M.: Fuel mixture comprising polyoxymethylene dialkyl ether. Patent (WO 2008074704); 12.12.2007 (2007)

32. Tebben, G.D., Schelling, H., Ströfer, E., Pinkos, R., Haunert, A., Eiermann, M., Karl, J.: Biodiesel fuel mixture containing polyoxymethylene dialkyl ether. Patent (WO 2007000428); 26.06.2006 (2006)

33. Burger, J., Hasse, H.: Multi-objective optimization using reduced models in conceptual design of a fuel additive production process. Chem. Eng. Sci. 99, 118-126 (2013)

34. Burger, J., Ströfer, E., Hasse, H.: Production process for diesel fuel components poly(oxymethylene) dimethyl ethers from methanebased products by hierarchical optimization with varying model depth. Chem. Eng. Res. Design 91, 2648-2662. https://doi. org/10.1016/j.ces.2013.05.049 (2013)

35. Schmitz, N., Burger, J., Ströfer, E., Hasse, H.: From methanol to the oxygenated diesel fuel poly(oxymethylene)dimethyl ether: an assessment of the production costs. Fuel J. 185, 67-72 https://doi. org/10.1016/j.fuel.2016.07.085 (2016)

36. Sauer, J., Arnold, U., Dahmen, N.: Synthetic fuels from biomass: potentials and viability. Springer Fachmedien Wiesbaden 2016. J.
Liebl, C., Beidl (Hrsg.);https://doi.org/10.1007/978-3-658-12918 -7_34. Internationaler Motorenkongress (2016)

37. Arnold, U., Lautenschütz, L., Haltenort, P., Niethammer, B., Oestreich, D., Sauer, J.: Alternative diesel fuels: Feedstocks, production and potentials; Nikolai Schubert (Hrsg.). In: 11th International Colloquium Fuels; Ostfildern, June 27-29 (2017)

38. Kaltschmitt, M., Hartmann, H., Hofbauer, H.: Energie aus biomasse. Springer, Berlin, Heidelberg. ISBN 978-3-540-85095-3 (2009)

39. Petersen, S.: Carbo-V® biomass gasification technology: status after application of sound engineering practices (2015)

40. Linde, A.G.: Engineering Division, Dr.-Carl-von-Linde-Strasse 6-14, 82049 Pullach G Discover the Carbo-V® process

41. UOP Selexol ${ }^{\mathrm{TM}}$ Technology for Acid Gas Removal; UOP 5241; https://www.uop.com/?document=uop-selexol-technology-foracid-gas-removal \&download=1 (2009)

42. Air products liquid phase conversion company Commercial-scale demonstration of the liquid phase methanol (LPMEOH) process, (2004)

43. Reuss, G., Disteldorf, W., Gamer, A.O., Hilt, A.: Formaldehyde. https://doi.org/10.1002/14356007.a11_619 Ulmann's Encycl. pp. 735-768, (2000)

44. Grützner, T., Lang, N., Siegert, M., Ströfer, E., Hasse, H.: Development of a new distillation based process for trioxane production. Institution of chemical engineers. ISBN 0-85295-505-7 Institution of chemical engineers symposium series, vol. 152; p. 336-343; Distillation and absorption 2006, Distillation and Absorption Conference, p. 8 (2006)

45. Liu, H., Gao, H., Ma, Y., et al.: Synthesis of high-purity methylal via extractive catalytic distillation. Chem. Eng. Technol. 35, 841-846 (2012). https://doi.org/10.1002/ceat.201100446

46. Pickett, L., Siebers, D., Idicheria, C.: Relationship between ignition processes and the lift-off length of diesel fuel jets; SAE paper 2005-01-3843; ISSN 0148-7191; https://doi. org/10.4271/2005-01-3843

47. Drack, J.: Bewertung der Herstellung von sauerstoffhaltigen Dieselersatzkraftstoffen durch indirekte Biomasseverflüssigung, Diplomarbeit, Graz University of Technology (2015)

48. Ulrich, G.D., Vasudevan, P.T.: Chemical engineering process design and economics: a practical guide. Process Publishing. ISBN 0970876823, 9780970876829 (2004)

49. Zhu, Y., Hinds, W.C., Kim, S., Sioutas, C.: Concentration and size distribution of ultrafine particles near a major highway. J. Air Waste Manag. Assoc. 52, 1032-1042 (2002)

50. Pelerin, D., Gaukel, K., Härtl, M., Wachtmeister, G.: Simplifying of the fuel injection system and lowest emissions with the alternative diesel fuel oxymethylene ether. In: Proceedings of the 16th Conference "The Working Process of the Internal Combustion Engine”, September 28-29, 2017; Graz (2017)

Publisher's Note Springer Nature remains neutral with regard to jurisdictional claims in published maps and institutional affiliations. 